\title{
Autologous Bone Marrow-derived CD34/CXCR4-positive Stem Cells AMR-001
}

National Cancer Institute

\section{Source}

National Cancer Institute. Autologous Bone Marrow-derived CD34/CXCR4-positive Stem

Cells AMR-001. NCI Thesaurus. Code C103865.

A cell-based product containing autologous bone marrow derived CD34 positive and C-XC chemokine receptor type 4 (CXCR4) positive stem cells with potential antiapoptotic and proangiog enic activities. Upon intracoronary infusion after a myocardial infarction (MI), autologous bone marrow-derived CD34/CXCR4-positive stem cells may preserve cardiac muscle cells and prevent apoptosis; thus improving myocardial perfusion. CD34/CXCR4positive stem cells are naturally mobilized upon cell injury through signaling by hypoxia inducing factor (HIF), which is secreted in response to hypoxia. In turn, HIF induces the synthesis of stromal-derived factor 1 (SDF-1) and vascular endothelial growth factor (VEGF) which mobilize CD34/CXCR4 positive stem cells; CXCR4 is the receptor for stromal-derived factor 1 (SDF-1). 